auf eine Enzym-Wirkung und die Beschaffenheit dieses Enzymes zurückführen zu müssen.

Die von ihm nach vielen. Untersuchungsergebnissen angeführten Gründe sprechen allerdings für diese Behauptung und würden auch mit der oben erwähnten Ansicht von Kosutány insofern in Einklang stehen, als nach letzterem das Gliadin sich durch Anlagerung von Wasser aus dem Glutenin bilden soll. Weil man aber sowohl aus dem natürlichen Weizenmehl wie aus getrocknetem Kleber durch 60-70\%-igen Alkohol das "Gliadin" (wie ebenso das Fibrin und Mucedin) ausziehen kann, durch Alkohol von dieser Stärke die Enzyme aber unwirksam bezw. ausgefällt werden, so erscheint eine Enzym-Wirkung bei der Bildung der in Alkohol löslichen KleberProteinstoffe ausgeschlossen und würde dieselbe nur für die Bildung des Glutenins angenommen werden können. Dieses soll sich aber nach Kosutány durch Wasserabspaltung aus dem Gliadin bilden und würde man, falls ein Enzym bei der Kleberbildung nach Stein mitwirken und die Ansicht Kosutány's über die Bildung von Glutenin aus dem Gliadin durch Wasserabspaltung und umgekehrt über die Bildung von Gliadin aus dem Glutenin durch Wasseranlagerung richtig sein sollte, annehmen müssen, daß wir es im Weizen mit einem Enzym zu tun haben, welches ähnlich wie die Lipase, die sowohl Fette zu spalten als aus Fettsäuren und Glycerin Fette zurückzubilden imstande sein soll, bald Wasser anlagern bald abspalten also invers wirken kann.

Man sieht hieraus, daß die wichtige und viel bearbeitete Frage über die Beziehungen des Klebers zur Backfähigkeit der Mehle noch lange nicht gelöst ist und daß noch wohl andere als die vorstehend angegebenen Wege eingeschlagen werden müssen, um die Ursachen, von denen die Backfähigkeit der Mehle abhängig ist, völlig aufzuklären.

\title{
Über das mittlere Molekulargewicht der nichtflüchtigen Fettsäuren holländischer Butter.
}

\author{
Von \\ Dr. A. Olig und Dr. J. Tillmans. \\ Vorläufige Mitteilung aus dem staatlichen Untersuchungsamt fír die \\ Auslandsfleischbeschau in Emmerich.
}

Bei dem allgemeinen Interesse, das die holländische Butter angesichts der raffiniert ausgeführten Fälschungen derselben in einem Teil der niederländischen Molkereien zur Zeit in Anspruch nimmt, untersuchen wir schon seit Januar dieses Jahres im Auftrage der Könglichen Regierung zu Düsseldorf gewisse am hiesigen Orte zur Einfuhr gelangende holländische Butter. Da bei dem Schwanken der chemischen Konstanten der Butter eine raffinierte Fälschung unserer Ansicht nach nur dann sicher nachgewiesen werden kann, wenn gleichzeitig zweifellos reine Naturbutter derselben Zeit und Gegend zum Vergleiche mit untersucht wird, so erwirkte das biesige Untersuchungsamt bei der Regierung die Genehmigung. zur Einfuhr von Milch aus Holland.

Die eingeführte Milch haben wir selbst verbuttert und die gewonnene Butter in Gemeinschaft mit dem zweiten Assistenten des Untersuchungsamtes, Herrn Stumpf, 
einer eingehenden Untersuchung unterworfen. Diese Versuche sind vom Juni dieses Jahres bis jetzt fortgeführt und sollen auch den Winter hindurch fortgesetzt werden.

Wenn wir nun die Ergebnisse unserer Untersuchungen bisher noch nicht der Offentlichkeit übergeben haben, so liegt das daran, daß wir ein abschließendes Urteil über die mittlere Zusammensetzung holländischer Butter der in Betracht kommenden Gegend nach so kurzer Zeit noch nicht abgeben zu können glaubten und weil wir der Ansicht sind, daß bei der schwankenden Zusammensetzung der Butter zu den verschiedenen Zeiten des Jahres unsere Untersuchungen sich mindestens über den Zeitraum eines Jahres erstrecken müssen, um ein einigermaßen sicheres Urteil sich bilden zu können,

Die überraschenden Ergebnisse jedoch in bezug auf das mittlere Molekulargewicht der nichtflüchtigen Fettsäuren, die in. Widerspruch zu den Befunden $J$ uckenack's und Pasternack's ${ }^{1}$ ) stehen, durch Beobachtungen von $A$. Reinseh ${ }^{2}$ ) aber bestätigt werden, veranlassen uns, unsere Beobachtungen in dieser Hinsicht schon jetzt zu veröffentlichen, um die Fachgenossen darauf aufmerksam zu machen, zu welchen irrigen Schlußfolgerungen man bei der Beurteilung einer Butter auf Grund des mittleren Molekulargewichtes der nichtflüchtigen Fettsäuren gelangen kann.

Wir beschränken uns hier darauf, die Werte für die Reichert-Meibl'sche Zahl und das mittlere Molekulargewicht mitzuteilen und bemerken, dafo alle Bestimmungen ganz unabbängig voneinander meist dreimal ausgeführt wurden.

Die Beobachtung von Reinsch, daß durch zu langes Stehenlassen der Fettsäuren auf dem Wasserbade leicht ein zu hohes Molekulargewicht gefunden wird, können auch wir bestätigen. Wir haben uns deshalb stets bemüht, nachdem die Fettsäuren von den letzten Resten des Äthers befreit waren, dieselben sofort zu titrieren.

Die Butter wurde hergestellt aus je 5 l Milch von Gendringen in Holland und Umgegend.

Die Untersuchungsergebnisse, die sich auf das klar filtrierte Fett beziehen, waren folgende:

\begin{tabular}{|c|c|c|c|c|c|}
\hline $\begin{array}{l}\text { Tag der } \\
\text { Entnahme } \\
\text { der Milch }\end{array}$ & $\begin{array}{c}\text { Reichert- } \\
\text { MeißI'sche } \\
\text { Zabl des } \\
\text { Milchfettes }\end{array}$ & $\begin{array}{l}\text { Mittleres Mole- } \\
\text { kulargewicht der } \\
\text { nichtflichtigen } \\
\text { Fettsäuren }\end{array}$ & $\begin{array}{l}\text { Tag der } \\
\text { Entnahme } \\
\text { der Milch }\end{array}$ & $\begin{array}{c}\text { Reichert- } \\
\text { Meif I'sche } \\
\text { Zahl des } \\
\text { Milchfettes }\end{array}$ & $\begin{array}{c}\text { Mittleres Mole- } \\
\text { kulargewicht der } \\
\text { nichtflïchtigen } \\
\text { Fettsäuren }\end{array}$ \\
\hline 1. VI. 04 & 26,3 & 260,1 & 27. VIII. 04 & 23,3 & 265,4 \\
\hline 1. VI. 04 & 29,6 & 258,8 & & 21.4 & 264,7 \\
\hline 1. VI. 04 & 29,5 & 261,0 & $\begin{array}{l}\text { 10. IX. 04 } \\
\text { 10. IX. } 04\end{array}$ & $\begin{array}{l}21,4 \\
26,9\end{array}$ & $\begin{array}{l}204,4 \\
269,4\end{array}$ \\
\hline 18. VI. 04 & 32,2 & 260,3 & 10. IX. 04 & 23,2 & 269,3 \\
\hline 18. VI. 04 & 29,5 & 261,8 & 17. IX. 04 & 29,9 & 265,3 \\
\hline 18. VI. 04 & 29,5 & 259,5 & 17. IX. 04 & 25,4 & 269,2 \\
\hline 25. VI. 04 & 31,1 & 260,0 & 17. IX. 04 & 24,4 & 271,6 \\
\hline 25. VI. 04 & 32,6 & 255,4 & 1. X. 04 & 25,6 & 264,1 \\
\hline 25. VI. 04 & 28,2 & 264,1 & 1. X. 04 & 20,9 & 261,3 \\
\hline 20. VIIT, 04 & 25,7 & 270,2 & 1. X. 04 & 23,9 & 257,8 \\
\hline 20. VIII. 04 & 29,1 & 267,3 & & & \\
\hline 20. VIII. 04 & 25,5 & 271,5 & & & \\
\hline
\end{tabular}


Dass nicht allein holländische Butter diese hohen Molekulargewichte aufweist, beweisen die folgenden Befunde bei einem Butterfette, das aus Mischmilch von etwa 1000 Kühen aus der Molkerei Grieshausen bei Cleve von uns selbst verbuttert worden ist:

$\begin{array}{ccc}\text { Tag der Entnahme } & \begin{array}{c}\text { Reichert-Meißl'sche Zahl } \\ \text { der Milch }\end{array} & \begin{array}{c}\text { Mittleres Molekulargewicht } \\ \text { der nichtfluchtigen Fettsäuren }\end{array} \\ \text { 25. VIII. 04 } & 26,1 & 267,1 \\ \text { 25. VIII. 04 } & 25,0 & 267,3 \\ \text { 25. VIII. 04 } & 26,0 & 266,6\end{array}$

Aus diesen Zahlen scheint uns hervorzugehen, daf das mittlere Molekulargewicht der nichtflüchtigen Fettsäuren der Butter im Sommer meist, jedoch nicht immer, innerhalb der von Juckenack und Pasternack angegebenen Grenzen liegt. Im Herbst jedoch erhebt sich das mittlere Molekulargewicht meist weit über die von den genannten Autoren angegebenen Zahlen. Ob diese Erscheinung vielleicht in den ungünstigen Fütterungsverhältnissen dieses Sommers, in dem infolge der anhaltenden großen Dürre vielen Landwirten schon im Sommer Grünfutter nicht mehr zur Verfügung stand und dasselbe durch Trockenfutter und Kraftuttermittel ersetzt werden mußte, mit ihren. Grund hat, mag dahingestellt bleiben.

Jedenfalls aber zeigen diese Zahlen, daß es unmöglich ist, eine Butter auf Grund eines Molekulargewichtes von über 261 für verfälscht zu erklären. Im übrigen behalten wir uns vor, einen eingehenden Bericht über die sonstigen Ergebnisse unserer Versuche im nächsten Jahre in dieser Zeitschrift zu veröffentlichen.

\title{
Ein Beitrag zur Untersuchung des schwarzen Thees.
}

\author{
Von
}

\section{Armin Röhrig.}

Mitteilung ans der Chemischen Untersuchungsanstalt der Stadt Leipzig.

Für den praktischen Nahrungsmittelchemiker bieten die chemischen Untersuchungen des Thees im allgemeinen wohl nur wenig Interesse. Es mag diesem Umstande allein die Ursache zuzusprechen sein, daß die Literatur der Theeprüfungen gegenüber der anderer Genußmittel nicht umfangreich und noch erweiterungsfähig ist.

Im gewöhnlichen Gange der regelmäßigen Nahrungsmittelkontrolle unserer Untersuchungs-Anstalt hatten wir zu Beginn unserer Tätigkeit dem Handel mit Thee unsere besondere Aufmerksamkeit geschenkt, um, wie dies auch anderwärts geschehen ist, auch hier den Nachweis des reellen Gebahrens zu erbringen. Wie vorauszusehen war, bat sich dies im vollen Umfange bestätigt; auch in unserem Stadtgebiete hat eine Theefälschung nicht ermittelt werden können, und wir glauben auch annehmen zu dürfen, dafo diese überhaupt $z u$ den großen Seltenheiten gehört. Trotz des zunehmenden Theeverbrauchs ist Deutschland doch noch zu den mäbigsten Verbrauchern zu zählen; Verfälschungen aber werden böchst wahrscheinlich vorwiegend nur dort vorkommen, wo sie am lohnendsten sind.

Unsere Arbeit, die sich im üblichen Rahmen der Untersuchung bewegte, und 